\title{
Razão, filosofia e formação em Max Horkheimer*
}

\author{
Reason, Philosophy and Education (Bildung) in Max Horkheimer
}

\author{
Franciele Bete Petry \\ ffpetry@yahoo.com.br \\ (Universidade Federal de Santa Catarina, Santa Catarina, Brasil)
}

\begin{abstract}
Resumo: 0 artigo busca discutir a função social atribuída à filosofia por Horkheimer levando em consideração sua crítica à razão. Esta será reconstruída na primeira seção, a qual mostrará como a razão sofreu um processo de esvaziamento de seus conteúdos objetivos, o que resultou no predomínio de uma razão instrumental orientada para a mera autoconservação do indivíduo. $\mathrm{Na}$ segunda seção, discutiremos a posição de Horkheimer de que a resistência a esse processo seria possível a partir do exercício de um pensamento não conformista, que se identifica à filosofia, e que busca trazer razão ao mundo ao refletir criticamente sobre a estrutura social e suas contradições. Destacaremos, por fim, a importância da formação (Bildung) no contexto da Universidade, instituição valorizada por Horkheimer pelo humanismo capaz de mobilizar para a resistência.
\end{abstract}

Palavras-chave: Max Horkheimer; razão; filosofia; formação (Bildung).
Abstract: The paper aims to discuss the social function attributed by Horkheimer to philosophy considering his critique of reason. In the first section, we will examine Horkheimer's view that reason has suffered a process that dissolved its main contents. This process has resulted in the predominance of an instrumental reason oriented by mere selfpreservation of the individual. In the second section, we shall discuss Horkheimer's view of resistance to this process: it would be possible as a non-conformist thinking that is identical to philosophy and tries to bring reason to the world by understanding and criticizing the social structure and its contradictions. At the end, we will highlight the importance of education (Bildung) in the context of University, which is an institution viewed by Horkheimer as a place for humanism, able to mobilize individuals for resistance.

Keywords: Max Horkheimer; Reason; Philosophy; Education (Bildung).

\section{Crise da razão e do indivíduo}

A defesa de que cabe à filosofia uma função social é feita a partir de uma determinada compreensão da realidade, mais precisamente, com base na interpretação de que as estruturas racionais que devem compor a sociedade se encontram fragilizadas; de que a sociedade vivencia um contexto de crise da razão e do indivíduo. Os argumentos relativos a esse diagnóstico feito por Horkheimer podem ser encontrados em dois de seus escritos, um, datado de 1941, intitulado 0 fim da

* Este trabalho foi realizado com apoio financeiro da CAPES durante a realização de estágio pósdoutoral no exterior, processo n.6730/14-0. 
razão, e outro, mais conhecido, Eclipse da razão, publicado em 1947. ${ }^{1}$

Em O fim da razão, Horkheimer explicita o movimento que reduz a razão a uma função de autopreservação do indivíduo. Segundo ele, entre os conceitos da civilização, os quais estariam em um processo de decadência, há um que se mostra decisivo e é, inclusive, de maior importância para a filosofia, a saber, o de razão: "ele é concebido para ordenar as relações entre os homens e justificar todas as ações (performances) demandadas por eles" (Horkheimer, 1941b, p.366). É a partir desse conceito que se justificam, internamente, ideias centrais, como as de liberdade, justiça e verdade. Na tradição filosófica, especialmente no racionalismo, as categorias associadas à razão, como as de mente, vontade, causa final, ideias inatas, dentre outras, passaram a ser, de acordo com Horkheimer, vistas como "símbolos sem sentido, uma figura alegórica sem função, e todas as ideias que transcendem a realidade dada são forçadas a compartilhar sua desgraça (idem, p.367). Contudo, a razão não foi deixada de lado completamente: permaneceu no vocabulário revestida por um sentido pragmático. Ela passa a se relacionar a um cálculo entre meios e fins, a uma operação que otimiza a ação para alcançar um determinado objetivo.

Esse caráter instrumental sempre esteve ligado à razão, porém, tornou-se problemático principalmente na modernidade. Para Horkheimer, a razão transformouse em um instrumento que auxilia os indivíduos a realizarem seus interesses por meio de uma organização social. Assim, eles ajustam sua existência dentro da coletividade de modo a obter dela aquilo que, isolados, não conseguiriam. A razão serve, portanto, como uma regulação entre os interesses dos indivíduos e os da sociedade. Em sociedades cuja estrutura estava organizava em torno da razão, era possível alcançar uma harmonia entre tais interesses. O problema, para Horkheimer, é que essa sociedade harmônica não se estabelece, exceto, talvez, na Grécia Antiga, pois do indivíduo é exigido, sempre, a adaptação às normas e leis sociais. Para Horkheimer, "o indivíduo tem que fazer violência a si mesmo e aprender que a vida do todo é pré-condição necessária à sua” (Horkheimer, 1941b, p.369). Nessa dinâmica, a razão fica encarregada de disciplinar os sentimentos e instintos rebeldes e fazer com o que o indivíduo internalize a exigência de adaptação. Quanto mais sucesso for obtido com esse mecanismo, mais a sociedade alcança seu progresso. De acordo com Horkheimer, "para aqueles na base da pirâmide social, porém, a harmonia entre o interesse universal e o individual foi meramente um postulado" (idem, p.370) e

\footnotetext{
1 Apesar de algumas das ideias defendidas nesses dois escritos possuírem afinidade com as teses da obra conjunta de Horkheimer com Theodor W. Adorno, Dialética do esclarecimento, optamos por não tratar dessa última no presente texto, uma vez que exigiria ampliar o debate sobre as posições dos autores para além dos objetivos a que nos propomos neste momento. Exemplo disso é a discussão sobre a continuidade ou não do pensamento de Horkheimer apresentado nos escritos da década de 1940 nas teses da Dialética do esclarecimento ou mesmo em sua obra tardia. Neste trabalho, procuramos mostrar que há posições sustentadas por Horkheimer da década de 1940 que são mantidas em escritos posteriores do início da década de 1950 citados neste artigo.
} 
sua sociabilidade teve que ser alcançada à força. A impossibilidade de haver essa conciliação de interesses desmente a universalidade da razão, a qual pressupõe que haja, de fato, uma comunidade entre os homens. Na verdade, essa universalidade vai se tornando cada vez mais formal, passando a ser compreendida em termos de autopreservação do indivíduo, algo que constituía uma de suas finalidades, mas não a única, e tampouco se expressava de modo tão reduzido.

As implicações, de acordo com Horkheimer, dizem tanto respeito ao plano teórico, quanto à organização social. Por um lado, a razão, ao ser definida em termos da autopreservação individual, não mais ampara a justificação de ideias universais, cujos opostos ganham o mesmo status. Assim, por exemplo, escolher entre a liberdade e a obediência, entre a democracia e o fascismo, seria resultado de uma preferência subjetiva (cf. Horkheimer, 1941b, p.371). Entretanto, mesmo a escolha individual é restrita à autopreservação das classes superiores, cuja manutenção dos privilégios foi "o único critério que determinou se se deveria lutar contra ou conspirar a favor de outros interesses e grupos, se deveria manter um governo constitucional ou dar um passo em direção ao autoritarismo" (idem, ibidem). O fim de autopreservação do indivíduo se revela, desse modo, contrário ao seu próprio interesse, pois a troca não se dá conforme o esperado. O sacrifício subjacente a tal lógica seria racional se, de fato, os indivíduos tivessem asseguradas suas necessidades, se o fim das ações estivesse dirigido ao desenvolvimento do homem.

Em sua análise das tendências que predominaram na sociedade europeia ao longo dos séculos, Horkheimer critica também a ideia de autonomia tão defendida no período iluminista e que não teria escapado ao movimento de formalização da razão. Ela se revelou ilusória e não sobreviveu ao processo de industrialização, o qual passou a dispensar o próprio exercício crítico que fazia parte da razão. A substancialidade do indivíduo se perde em meio às renúncias que ele faz em nome da ordem social. A própria família sofre uma transformação que dissolve seu poder de formação e proteção do indivíduo. Para Horkheimer, os indivíduos contemporâneos devem desenvolver mais a presença de espírito que os músculos, devem ter respostas prontas e uma afinidade com todo o tipo de máquinas, sejam elas técnicas, esportivas ou políticas (Cf. Horkheimer, 1941b, p.378). Essa adaptação ao processo de industrialização torna sem sentido o pensamento reflexivo e a própria teoria, já que não cumprem nenhuma função dentro do aparato técnico. A ligação entre a razão e a eficiência se torna ainda mais exacerbada, pois o centro da ação humana está no trabalho - que o indivíduo deve realizar de forma produtiva. Como diz Horkheimer, "a falta de eficiência é uma ofensa capital” (idem, p.379).

A absorção da esfera econômica pelo âmbito privado se apresenta, então, como um problema, uma vez que impede a existência de uma oposição do indivíduo à coletividade. No texto Arte e cultura de massa, de 1941, Horkheimer defende 
que as famílias de classe média eram, ao mesmo tempo, agências que tornavam os padrões socais obsoletos e, por outro lado, criadoras de uma mentalidade aberta às diferentes potencialidades que o indivíduo poderia ter, para além do trabalho ou vocação. Ele as compara a um segundo útero que dá origem ao nascimento social do indivíduo. A família cumpriria uma função fundamental no desenvolvimento do ser humano, dando-lhe um “calor acolhedor e confortável” que ampara o indivíduo e cria sua força de resistência, funcionando, portanto, como um refúgio da sociedade, tal como a arte. Contudo, ao ser invadida, cada vez mais, pela esfera social, o âmbito privado da família deixa de cumprir aquela função de preservação do indivíduo e de garantir a ele um certo sentido de liberdade.

Essa ideia de uma integração do indivíduo à sociedade aparece no texto Arte e cultura de massa e remete a uma consideração semelhante presente em $O$ fim da razão: Horkheimer chama a atenção para o fato de que é exigido dos homens que arrisquem sua vida pela liberdade, pela democracia ou pela nação, apesar dessa demanda ser absurda, já que não existem mais valores capazes de unir os homens (Horkheimer, 1941a, p.299) e justificar tal forma de renúncia. Nem mesmo a religião foi capaz de dar sentido ao sacrifício, pois as exigências da sociedade são tão fortes que se impõem como uma necessidade ao indivíduo. Por isso, diz Horkheimer, eles são tão tristes: "quanto mais fracos eles são e mais profundamente desapontados, mais violentamente eles adotam a brutalidade" (idem, ibidem).

Em Eclipse da razão, obra que reúne cinco conferências proferidas no ano de 1944, mas somente publicadas em 1947, Horkheimer desenvolverá sua crítica a partir de um conceito duplo de razão. Em suas conferências, ele distingue, por um lado, a dimensão objetiva da razão, correspondente a uma atividade de definição de fins para as ações, enquanto a parte subjetiva estaria relacionada ao funcionamento abstrato do mecanismo de pensamento responsável por coordenar os meios em relação aos fins. Para Horkheimer, houve um tempo, especialmente na Grécia Clássica, em que a razão não aparecia de forma tão cindida, pois funcionava em harmonia a partir dessas duas dimensões. A razão subjetiva era necessária para realizar os fins que a parte objetiva determinava como importantes para a existência humana. Tais fins estão ligados a certa ordenação racional da realidade conciliada com os interesses de autopreservação do indivíduo, sendo expressos na forma de conceitos. A dimensão objetiva, nesse sentido, pode ser concebida como um princípio estruturante da realidade, mas que se reflete, também, no esforço filosófico de organizar essa realidade tendo como referência a ideia de uma totalidade. A crítica de Horkheimer é a de que a crise da razão

consiste fundamentalmente no fato de que, a certa altura, o pensamento tornouse simplesmente incapaz de conceber tal objetividade ou começou a negá-la como ilusão. Esse processo avançou gradualmente até incluir o conteúdo objetivo de todo 
conceito racional. Ao final, nenhuma realidade particular pode parecer razoável per se; todos os conceitos básicos, esvaziados de seu conteúdo, tornaram-se apenas carapaças formais. Na medida em que a razão é subjetivada, ela também se torna formalizada (Horkheimer, 2015, p.15).

Uma das implicações mais importantes dessa tese está na impossibilidade de fundamentarmos os fins de nossas ações em critérios racionais, pois eles seriam, antes, objetos de escolha ou predileção. Para Horkheimer, então, falar de uma "verdade" nas esferas da moral, estética ou da prática se torna algo sem sentido. Sem a razão como determinante dos fins, ficamos à mercê dos conflitos de interesses, sem uma autoridade objetiva que possa reclamar validade universal para as ações na vida social ou individual. Um exemplo fornecido por Horkheimer sobre uma das consequências desse fenômeno é o de que a democracia, sem esse fundamento racional, tornar-se-ia frágil, já que seria guiada pelos interesses do povo, os quais, por sua vez, se orientariam por forças econômicas ou cegas, ou muito conscientes (Cf. Horkheimer, 2015, p.37). De modo análogo às conclusões a que chegou no escrito O fim da razão, Horkheimer não considera possível, nessas condições, fugir de um relativismo que impediria, por exemplo, afirmarmos que a ditadura é má, já que tal juízo carece de um fundamento objetivo, podendo ser má somente para aqueles que não se beneficiam dela. O contrário, porém, seria igualmente válido. A razão objetiva, nesse contexto político, é substituída pela ideia da maioria, tal como se pode observar nesta passagem:

Hoje, a ideia de maioria, destituída de seus fundamentos racionais, assumiu um aspecto completamente irracional. Toda ideia filosófica, ética e política - cortados os laços que a relacionavam com suas origens históricas - tem uma tendência a tornarse o núcleo de uma nova mitologia, e essa é uma das razões pelas quais o avanço do esclarecimento tende, em certos pontos, a inverter-se em superstição e paranoia. 0 princípio da maioria, na forma de vereditos populares sobre todo e qualquer tema, implementado por todos os tipos de sondagens e modernas técnicas de comunicação, tornou-se a força soberana à qual o pensamento deve servir. É um novo deus, não no sentido em que os arautos das grandes revoluções o concebiam, a saber, como um poder de resistência a tudo que não se conforma. Quanto mais o julgamento das pessoas é manipulado por todos os tipos de interesse, mais a maioria é apresentada como árbitra na vida cultural. Ela deve justificar os substitutos da cultura em todos os seus ramos, até os produtos da arte e da literatura populares que iludem as massas. Quanto mais a propaganda científica faz da opinião pública uma mera ferramenta de forças obscuras, mais a opinião pública aparece como uma substituta da razão. Esse triunfo ilusório do progresso democrático consome a substância intelectual da qual a democracia tem vivido (Horkheimer, 2015, p.39).

A constatação feita no escrito $O$ fim da razão, de que a ideia de razão foi mantida no vocabulário, embora já sem representar uma instância de validade universal, aparece também nessas conferências. Horkheimer defende, com um tom radical, que sem uma dimensão objetiva para determinar os fins, caímos em uma 
forma de relativismo que toma as coisas sempre em referência a algum interesse subjetivo ou a um padrão de medida que se tornou característico da modernidade, qual seja, o tempo. Para a razão formalizada, tais critérios se apresentam com força e impossibilitam uma atribuição de valor às ações humanas independentemente daquilo que elas possam trazer de benefício ao sujeito. De acordo com Horkheimer,

pode parecer sem sentido considerar um modo de vida particular, uma religião, uma filosofia, melhor ou mais elevado ou mais verdadeiro que outro. Uma vez que os fins não são mais determinados à luz da razão, é também impossível dizer que um sistema econômico ou político, não importa quão cruel ou despótico, seja menos razoável que outro. De acordo com a razão formalizada, o despotismo, a crueldade, a opressão não são ruins em si; nenhuma agência racional endossaria um veredito contra uma ditadura se seus apoiadores pudessem lucrar com ela (Horkheimer, 2015, p.40).

Mas também em relação às ações mais cotidianas a ideia se aplica: já que, por exemplo, as experiências estéticas foram destituídas do contexto que lhes conferia significado, justifica-se sua permanência, agora, com outro objetivo, como o entretenimento, a diversão ou o lazer. Houve, assim, uma incorporação da própria ausência de significado das ações ao modo de vida já organizado segundo a razão formalizada e isso ocorreu na medida em que ela se transformou em instrumento para alguma outra finalidade. Como diz Horkheimer,

cada vez menos algo é feito como um fim em si. Uma caminhada que leve um homem para fora da cidade, à margem do rio ou ao cume de uma montanha, seria considerada irracional ou idiota, se julgada por padrões utilitaristas; ele dedica-se a um passatempo tolo ou destrutivo. Na visão da razão formalizada, uma atividade é razoável (racional) apenas quando serve a outro propósito, por exemplo, a saúde ou o relaxamento, que ajudam a recarregar as energias para o trabalho. Em outras palavras, a atividade é uma mera ferramenta, pois ela deriva seu sentido apenas do seu vínculo com outros fins (Horkheimer, 2015, p.46).

Essa instrumentalidade das ações está relacionada ao critério de medida do tempo, do qual outras ideias muito usuais são derivadas, tais como as de eficiência e utilidade. Elas podem ser usadas para justificar as ações, ocupando o espaço que antes pertencia à religião, à arte ou à política, lugares próprios da razão objetiva e de sua aspiração à verdade. Tal processo corresponde a uma reificação que, embora estivesse associada desde sua origem à sociedade organizada e ao uso de instrumentos, atinge um momento distinto na sociedade industrial quando todos os produtos da atividade humana se transformam em mercadorias. O significado das atividades passa a depender da sua utilidade, do fato de serem produtivas ou não, de atenderem de forma eficaz a certos propósitos. Isso mostra o quanto a vida passou a ser determinada por um processo de racionalização que, inclusive, irá afetar a dimensão pulsional, antes pertencente ao âmbito privado. Tendencialmente ocorre na esfera individual um ajustamento às demandas do sistema, as quais são 
prioritárias. Para Horkheimer, “da mesma forma como o processo de racionalização já não resulta de forças anônimas do mercado, mas é decidido na consciência de uma minoria planificadora, também a massa de sujeitos deve deliberadamente se ajustar" (Horkheimer, 2015, p.109). A autopreservação do sistema torna-se, assim, anterior à do sujeito.

Esse ajustamento tem uma consequência decisiva para a vida do indivíduo em sociedade, diagnóstico semelhante ao que já havia aparecido no texto 0 fim da razão. A realidade torna-se algo devastador, triunfa sobre o indivíduo, exigindo dele suas energias e sua submissão. A diferença em relação a outras épocas é que a adaptação não é mais feita em função do reconhecimento de uma autoridade, mas, sim, como desistência da própria individualidade. O homem, nesse contexto, vive em função da sua autopreservação, guiada, contudo, pela sociedade planificada. Os ideais de um homem livre e autônomo, ainda possíveis na fase do capitalismo liberal e no seio da família burguesa, agora são desmentidos facilmente. Horkheimer reconhece que houve um aumento da liberdade de escolha dos indivíduos, mas, em termos qualitativos, ela implicou uma mudança na própria ideia de liberdade, que passa a se dar dentro de um esquema fechado, o que revela, em última instância, que o indivíduo não pode escolher tanto assim. Essa ideia será depois desenvolvida na crítica à indústria cultural, mostrando como por trás da aparência de escolha existe algo planejado, pertencente não somente à esfera econômica, mas também política, à qual o indivíduo apenas reage e se adapta.

A critica à impossibilidade de uma escolha genuína envolve ainda outro elemento, qual seja, o de que a individualidade mesma está comprometida e, desse modo, sequer é possível fazer uma escolha consciente. 0 indivíduo não tem sua individualidade reforçada, antes, sacrifica-a. É somente quando se tem uma esfera privada, contraposta à pública, que o indivíduo poderia se afirmar. Tal como no texto O fim da razão, Horkheimer aponta para a dissolução das fronteiras que permitiam ao indivíduo resistir aos mecanismos sociais. Na era do liberalismo, viveu-se um individualismo exacerbado que escondia, porém, que os interesses buscados pelos indivíduos se subordinavam à razão autopreservadora, ou seja, cada indivíduo, convertido em uma mônada, buscava seu interesse e, dentro daquele contexto econômico, fazia a sociedade se desenvolver pela competição. Contudo, na passagem para o capitalismo tardio, o indivíduo já não é mais aquele que estabelece planos para sobreviver na lógica do livre mercado e que acreditava ser parte da coletividade. Nessa nova sociedade analisada por Horkheimer, o indivíduo está desamparado, pois perdeu sua sustentação na esfera econômica. Tem-se, assim, o declínio da própria individualidade:

ele [o indivíduo] simplesmente sente que não estará completamente perdido se preservar sua qualificação e o vínculo com sua corporação, associação ou sindicato. 
Assim, o sujeito individual da razão tende a tornar-se um ego atrofiado, cativo de um presente evanescente, esquecendo o uso das funções intelectuais pelas quais ele outrora foi capaz de transcender sua efetiva posição na realidade (Horkheimer, 2015, p.156).

Horkheimer deixa claro que a tendência predominante está em um tipo de homem submisso, que se comporta mimeticamente de acordo com os modelos exibidos por grupos sociais para, nessa adaptação, sobreviver junto a eles. A indústria cultural reforça a ideia de uma continuidade entre a vida privada e a realidade ao oferecer um retrato desta que oculta as relações que a produz: "o cinema, o rádio, as biografias e os romances populares têm o mesmo refrão: esse é nosso filão, esse é o canal para o grande e para aquele que se pretenda grande - está é a realidade como ela é e deveria ser e será" (Horkheimer, 2015, p.157). Entretanto, ele também reconhece que mesmo diante da força com que os mecanismos sociais e econômicos, assim como a cultura de massas, atuam na dimensão pulsional do indivíduo, modificando suas expectativas em relação ao que podem obter da realidade e, ao final, conformandose a ela, há, ainda assim, um poder de resistência. Diferentes passagens em suas conferências indicam essa possibilidade, por exemplo: “as massas, apesar da sua maleabilidade, não capitularam completamente à coletivização” (idem, p.159), ou, de que "existem algumas forças de resistência dentro do homem", pois, "é uma evidência contra o pessimismo social o fato de que, apesar do contínuo assalto de padrões coletivos, o espírito da humanidade esteja ainda vivo, se não no indivíduo como um membro de grupos sociais, pelo menos no indivíduo na medida em que é deixado sozinho" (idem, p.156).

É também interessante destacar que Horkheimer reconhece inclusive a existência de condições materiais relativas à cultura e tecnologia para permitir uma compreensão sobre as relações sociais que causam a opressão dos indivíduos, o que falta, porém, são homens que se proponham a pensar sobre isso. Nega, portanto, que devamos aceitar uma espécie de "imaturidade das massas", como se elas não pudessem chegar àquela compreensão. Essa possibilidade de resistência constituirá o objeto de discussão da segunda parte do presente trabalho.

\section{Filosofia, resistência e formação}

Nesta seção, procuraremos explicitar de que maneira a filosofia se apresenta como uma forma de resistência na medida em que cumpre uma função de formação do sujeito. A ideia principal a ser discutida é a de que, para Horkheimer, a força que pode tirar o indivíduo do fluxo de relações reificadas está no exercício de um pensamento não conformista. Claramente, não é um caminho para uma transformação social abrangente, mas é a possibilidade que se coloca no horizonte no plano individual 
e na qual se deve insistir. Além disso, buscaremos mostrar que esse pensamento de resistência está intimamente ligado ao exercício da filosofia.

Em primeiro lugar, é importante destacar que Horkheimer não considera possível oferecer uma definição do que seja a filosofia, pois ela corresponderia, segundo ele, “à exposição explícita do que ela tem a dizer” (Horkheimer, 2015, p.182). E embora atribua a ela um papel, isso não significa que ela deva consistir em um instrumento ou plano de ação, o que a inscreveria no âmbito da utilidade, contra a qual deveria se voltar.

Em seu texto A função social da filosofia, Horkheimer faz a seguinte suposição: imagine-se perguntando a um professor de filosofia em que esta consiste. Se tivermos sorte e encontrarmos alguém que não seja avesso às definições, ele nos dará uma. Mas mesmo que a aceitemos, logo viríamos a descobrir que ela está longe de ser o significado universalmente aceito para a palavra. Se consultarmos outras autoridades ou manuais, a confusão só aumentará (cf. Horkheimer, 1939/1940, p.322). Isso porque, explica Horkheimer, a situação da filosofia é muito peculiar em relação a outras áreas. Dentre as diferentes teorias possíveis, pode ocorrer de uma determinada corrente negar a outra tão enfaticamente que a substância do trabalho filosófico colocado em questão acaba sendo avaliado como falso. Assim, temos que partir do pressuposto de que quando falamos em "filosofia" sequer estamos diante de um consenso, antes, compartilhamos apenas algumas vagas concepções do que ela seja. Outra dificuldade apontada por Horkheimer é a de que, diferentemente da ciência, a qual se orienta a partir da prática da vida social, a filosofia não pode contar com tal critério. Ao contrário, na atual sociedade, tal como podemos ler em Eclipse da razão, "o pensamento que não serve aos interesses de qualquer grupo estabelecido ou que não é pertinente aos negócios de qualquer indústria não tem lugar, é considerado vão ou supérfluo" (Horkheimer, 2015, p.158), ou seja, da realidade, a filosofia deve esperar mais ser perseguida do que aceita, não exatamente por seu conteúdo, mas por seus princípios. Para Horkheimer, "a filosofia insiste que as ações e finalidades do homem não devem ser produto da necessidade cega" (Horkheimer, 1939/1940, p.325). Nada deveria ser aceito sem crítica somente porque faz parte dos costumes e práticas, sejam os conceitos da ciência ou os modos predominantes de pensamento. Por isso, à filosofia cabe certo tipo de esclarecimento que despe as ideias tanto quanto as relações sociais de seu caráter equivocadamente tido como natural, imutável ou eterno.

No texto mencionado, Horkheimer apresenta a preocupação também demonstrada em Eclipse da razão, a saber, que apesar do desenvolvimento científico e tecnológico, não há um avanço significativo em termos intelectuais ou no modo de agir dos indivíduos. Certamente, dado seu "não lugar" dentro da ordem social, não será apelando a uma forma de cientificismo que a filosofia poderia melhorar seu 
status, pois, assim, ao se "vender" e se mostrar útil, mostrar-se-ia, na verdade, servil às forças sociais. Ela se integraria ao preço da dissolução de seus princípios. Horkheimer recusa, portanto, essa atitude, assim como a visão de que a função social da filosofia seria idêntica a uma função ideológica. Ideologia é aqui entendida no sentido de que o pensamento seria meramente uma expressão de uma situação social específica (Horkheimer, 1939/1940, p.330) ou de um grupo social que o origina e ao qual está vinculado. Ainda que possa haver alguma verdade nessa ideia, diz Horkheimer, o pensamento tem que procurar compreender o processo histórico que abarca, inclusive, tais grupos sociais, aprofundando o exame das teorias filosóficas em sua vinculação com a base social. Mais importante do que isso, porém, é recusar nessa identificação da função social da filosofia com a ideologia que não seja possível sustentar mais nenhuma verdade.

Tampouco aqui cabe a defesa da transformação da filosofia em ciência ou em sociologia. Em última instância, "a função social da filosofia reside na sua crítica do que é predominante" (Horkheimer, 1939/1940, p.331) no sentido de "evitar que a humanidade perca a si mesma naquelas ideias e atividades que a organização social existente inculca em seus membros" (idem, ibidem). A ideia é a de fazer com que o homem, em vez de simplesmente atuar com o objetivo de alcançar determinados fins, veja a relação entre "suas atividades e o que por elas será alcançado, entre sua existência particular e a vida geral da sociedade, entre seus projetos diários e as grandes ideias que reconhece" (idem, ibidem).

Nesse contexto de reflexão, a filosofia pode expor as contradições com as quais o indivíduo se envolve e, assim, lutar pelo teor de verdade que ainda pode ser encontrado nesse exercício da razão. Horkheimer fornece um exemplo: nos diálogos de Platão podemos visualizar de que modo o pensamento dialético luta por eliminar a falsidade de toda opinião que se pretenda conhecimento. Por meio de um exame racional das ideias, é possível abandonar as aparências e, progressivamente, buscar um sentido verdadeiro para elas em conexão com um todo do conhecimento. 0 filósofo ser governante significaria então que não se tem fé no pensamento popular predominante, o qual deve ser examinado constantemente. E é nesse sistema de ideias, que atribui os sentidos sempre em conexão com um conhecimento mais abrangente, que pode existir "razão". A função social da filosofia deve ser esta: buscar desenvolver um pensamento dialético e crítico que coloque em questão aquilo que se aceita como predominante. Ela é, de acordo com Horkheimer, "uma tentativa metódica e obstinada de tentar trazer razão ao mundo. É disso que resulta sua posição precária e controversa" (Horkheimer, 1939/1940, p.332), pois a filosofia é inconveniente.

Apesar de podermos reconhecer mudanças no pensamento de Horkheimer nos escritos abordados em relação às suas reflexões tardias, podemos, porém, 
defender que há uma persistência utópica de que a filosofia insista em sua tarefa de buscar dar uma direção mais racional ao curso dos acontecimentos. Ela não deixa de conter, entretanto, um elemento aporético, pois essa tarefa se impõe em um mundo no qual ela não faz sentido, em uma realidade marcada pela reificação e pelo predomínio da razão instrumental que tende a uma marcha cega e regressiva. Como bem aponta Chiarello, os ideais da razão objetiva se revelam uma ilusão, "não obstante, a filosofia tardia de Horkheimer julga que é somente por meio deles que se pode fazer despertar a memória e recordar aos homens a esperança em algo além do existente" (Chiarello, 2001, p.165). O conteúdo disso que extrapola o existente e que justifica a insistência em um pensamento não conformista está, se não na consciência individual, mas "nas promessas utópicas da cultura, da arte e da religião de que o teórico crítico se faz representante e que sabe ilusórias - o que leva a extremos a situação paradoxal desse pensamento que se pretende materialista até a raiz" (idem, ibidem). Nesse sentido, para usar o termo empregado por Gambarotta, poder-se-ia falar em uma "utopia possível” (cf. Gambarotta, 2013, p.81), a qual se coloca como fundamento da própria teoria crítica, já que, ainda que a realidade imponha uma restrição quanto à realização de uma sociedade racional, o horizonte utópico nem por isso é puramente abstrato. Antes, o exercício da crítica que se faz no interior dessa sociedade em que ela não tem lugar contém em si um impulso de intervenção e transformação. No texto A função social da filosofia, Horkheimer havia afirmado que

nossa tarefa é assegurar que no futuro a capacidade para a teoria e para a ação que dela deriva nunca desapareça novamente, mesmo em um período vindouro de paz em que a rotina diária pode tender a permitir que todo o problema seja uma vez mais esquecido. Nossa tarefa é lutar continuamente para evitar que a humanidade se torne completamente abatida pelos terríveis acontecimentos do presente, evitar que a crença do homem em uma direção valiosa, pacífica e feliz para sociedade se extinga da terra (Horkheimer, 1939/1940, p.337).

Podemos observar que essa ideia permanecerá central no conjunto das preocupações de Horkheimer anos mais tarde. O exercício da crítica conterá uma dimensão formativa ligada, de forma mais específica, à pratica acadêmica. Ao retornar do exílio nos Estados Unidos e se tornar reitor da Universidade de Frankfurt na Alemanha, Horkheimer expressa em seus discursos o compromisso com a emancipação, valor presente como diretriz não apenas para a pesquisa acadêmica, mas também para os estudos e formação dos estudantes.

Em uma sociedade reificada, em que a natureza converte-se em mero material, o processo de formação entra em crise. Resistir a ela exigirá que se repense a maneira pela qual a consciência individual pode ser formada sem cair presa das tendências predominantes. Tal transformação se dá por meio de uma 
experiência diferenciada com a realidade, ideia, vale dizer, muito cara também a Adorno. A experiência, entendida em termos gerais, aponta para um estranhamento fundamental ao indivíduo a fim de desenvolver uma consciência de si inseparável da reflexão sobre o todo. Para Horkheimer, a Universidade, mais do que um lugar para se obter a especialização que busca garantir a base para o exercício profissional, abre-se à possibilidade de desenvolvimento do indivíduo, a essa experiência que recoloca a relação entre natureza, sociedade e razão. Para o autor, a formação (Bildung), possível na instituição acadêmica, é tanto

formação do todo exterior quanto, precisamente através disso, formação de si mesmo. Ninguém é formado sem que reconheça, na dedicação ao seu próprio objetivo, o nexo com o todo, e que, contra o espírito do tempo [Zeitgeist], empregue, também publicamente, aquela mesma liberdade - que se deve adquirir na profissão acadêmica de sua ciência face aos motes, clichês e preconceitos (Horkheimer, 1985a, p.416). ${ }^{2}$

A importância do espaço da Universidade como instância de formação está relacionada ao declínio de outra esfera antes responsável por cuidar da experiência do indivíduo. Como comentamos anteriormente, a família burguesa servia de proteção ao sujeito contra a força da coletividade, condição fundamental para uma atitude de resistência. Com o seu enfraquecimento, a lacuna aberta passou a ser ocupada por instâncias externas, as quais, porém, aprofundam a relação de dominação característica da sociedade contemporânea. A Universidade, orientada pela ideia de emancipação, pode promover uma experiência distinta aos indivíduos. Ela o faz na medida em que constitui um ambiente de convívio entre estudantes, professores, em que relações profundas são construídas com base em seu valor como fim em si, recusando sua redução a um interesse meramente instrumental. 0 ambiente universitário é favorável à mediação, imprescindível a uma experiência de abertura ao outro. É, por isso, o lugar em que uma comunidade se ergue a partir da ideia de formação e de outras a ela tão conectadas, como a de verdade, liberdade e da própria humanidade. Como bem explicita Klein em seu estudo sobre a relação entre a universidade e o conceito de formação, há nessa postura um compromisso com a democracia:

em sua interpretação do (desse) quadro de crise dos valores e da autoridade, de certa maneira, a escola superior precisaria, se não substituir, pelo menos auxiliar a família na reativação dos valores democráticos, ocupando, parcialmente, o vazio deixado pela reconfiguração da divisão do trabalho social de modo geral e que se expressa na mediação que o âmbito escolar faz com a vida diária. (...) E esses valores democráticos tomam como um dos pressupostos - talvez até mesmo aquele de maior relevância - a garantia de espaços para o debate de ideias, para a argumentação, através dos quais se poderia erigir processos cujo alcance seria significativamente maior do que aquele primariamente atribuído ao treinamento ou à preparação que

2 Gostaria de agradecer a Stefan Klein pela tradução das passagens citadas diretamente dos textos em alemão. 
caberia às instituições escolares (Klein, 2014, p.178). ${ }^{3}$

Tal defesa pode ser constatada também na conferência de Horkheimer de 1949, intitulada Filosofia e estudo (Philosophie und Studium). Nela, a universidade tem seu centro na formação, pois desenvolve a dimensão crítica do pensamento para além do conhecimento técnico que nela se busca. Horkheimer estaria defendendo o espaço da Universidade, para usar a expressão de Klein, como uma formação para a razão. Para isso, frente à especialização que caracteriza o trabalho acadêmico, e que é necessária, é preciso assegurar que a reflexão sobre o todo esteja presente, de modo a não tornar a produção do conhecimento algo mecânico e desconectado da reflexão sobre os fins a que se destina. Nesse sentido, é possível visualizar a afinidade entre a filosofia e a formação. Por meio de um pensamento não conformista, intransigente e que se opõe às tendências que atuam em relação à consciência das massas, o ambiente universitário pode promover uma formação capaz de mobilizar os indivíduos a darem ao mundo uma direção melhor. Reaparece, na conferência, a necessidade de que uma sociedade organizada racionalmente seja construída e sua possibilidade repousa na formação. Para Horkheimer, a Universidade pode contribuir para que o futuro seja assumido com mais responsabilidade pelos indivíduos e que não se encaminhe comodamente para um cego progresso. Assim, a Universidade mostra sua íntima relação com o humanismo, nos termos em que Horkheimer o explica:

Se o humanismo consiste em que a vida se oriente de acordo com a ideia, e não a ideia de acordo com a vida, então, hoje, voltar-se aos problemas políticos e sociais é uma tarefa verdadeira e urgentemente humanística da universidade. Penso, com isso, nem tanto na pronta adoção de todos e quaisquer métodos e técnicas das ciências sociais, que se desenvolveram em tão rica medida e em países tão variados durante as últimas décadas, embora o conhecimento crítico desses procedimentos não represente um elemento desimportante da auto-afirmação pensante na contemporaneidade. Ainda mais importante que tal conhecimento crítico é, no entanto, a análise impersuadível e a compenetração [Durchdringung] teórica das forças sociais. A teoria social e da sociedade [Gesellschafts- und Soziallehre] precisa, na universidade de hoje, ocupar um lugar mais importante do que em qualquer outra época (Horkheimer, 1985b, p.376).

A nova forma de organização social trouxe consigo tanto um enfraquecimento do pensamento crítico, quanto a adoção de novos critérios para o trabalho intelectual, como, por exemplo, o da produtividade e eficiência. Tal como se pode ler em Eclipse da razão, a eficiência se distingue de uma simples competência técnica ou administrativa. Trata-se, antes, de uma espécie de aderência do indivíduo ao esquema

\footnotetext{
3 Sobre a relação entre a universidade e o conceito de formação, recomendamos, além do artigo citado, a leitura da Tese de Doutorado de Stefan Fornos Klein, a qual constitui um excelente estudo: A universidade e a sociologia segundo Max Horkheimer: teoria, pesquisa e crítica (2012). Também importante para a discussão desse tema é o texto de Rafael Cordeiro Silva, Educação para a resistência em Max Horkheimer.
} 
da produção e ao ideal de produtividade, a partir dos quais se estabelece o valor do próprio indivíduo dentro da economia. Diferentemente da época da sociedade burguesa, em que a estabilidade proporcionada pelo acúmulo de riqueza permitia ainda preservar um ideal de cultivo do espírito humanista, nesse novo modelo de sociedade, o indivíduo, não mais independente, é obrigado a se integrar. Tal fenômeno é impulsionado, por um lado, pela cultura de massa e, por outro, precisamente por aqueles fins de produtividade e eficiência que se transformam no sentido das ações, já que asseguram sua utilidade prática tão almejada dentro desse esquema. Desse modo, o princípio da autopreservação funciona cegamente, absorvendo o indivíduo no processo de reificação. De acordo com Horkheimer,

em si, nem a tecnologia nem o ímpeto da autopreservação explicam o declínio do indivíduo; não é a produção per se, mas as formas nas quais se realiza - as inter-relações dos seres humanos dentro do enquadramento específico da industrialização. A labuta, a pesquisa e a invenção humanas são uma resposta ao desafio da necessidade. 0 padrão torna-se absurdo apenas quando as pessoas transformam a labuta, a pesquisa e a invenção em ídolos. Essa ideologia tende a suplantar a função humanística da própria civilização que busca glorificar (Horkheimer, 2015, p.169).

É contra essa tendência que a filosofia deve se opor, mostrando as contradições inerentes ao conceito de razão tal como se desenvolveu e as cisões que o predomínio da razão instrumental ocasiona na relação entre sujeito e objeto. Nesse sentido, a insistência em uma razão objetiva, tal como aparecia no texto Eclipse da razão, reveste-se, nas reflexões sobre Universidade e formação, de um caráter humanista, tão necessário para ampliar o horizonte da ação, conferindo a ela novos significados que sejam capazes de romper com os valores meramente instrumentais. Como afirma Horkheimer, só merece ser chamada de objetiva uma definição das finalidades objetivas da sociedade que inclua o propósito de autoconservação do sujeito, o respeito pela vida individual (Horkheimer, 2015, p.193). É preciso garantir que o interesse de autopreservação seja buscado em um contexto mais amplo, que não seja apenas de dominação da natureza e do próprio homem, algo impulsionado pela autocrítica da razão. Surge daí a importância da filosofia no sentido da formação, pois ela, segundo Horkheimer, "torna os homens conscientes da contradição entre eles. Por um lado, ela avalia a sociedade à luz das próprias ideias que esta reconhece como seus valores mais elevados; por outro, ela é ciente de que essas ideias refletem as máculas da realidade" (Horkheimer, 2015, p.193). Novamente, evidencia-se o caráter utópico e paradoxal do pensamento de Horkheimer, já que a crítica capaz de alterar o rumo de destruição progressiva do mundo parece ser tão mais necessária quanto menos é bem-vinda. Porém, como o próprio autor exprime em uma passagem do texto Arte e cultura de massa, tal insistência não é sem sentido, pois

um dia nós saberemos que, no fundo de seus corações, as massas, mesmo em países 
fascistas, secretamente conheciam a verdade e não acreditavam na mentira, como pacientes catatônicos que tornaram conhecido somente ao final de seu transe que nada lhes escapou. Por isso pode não ser completamente sem sentido continuar falando uma linguagem que não é facilmente entendida (Horkheimer, 1941a, p.304).

Assim, ainda que pareça impotente, ainda que pareça uma voz rouca a falar, sem ser ouvida, é preciso que a filosofia não se cale diante do sofrimento e da injustiça. Sua força expressiva intervém na realidade ao ser "a memória e a consciência do gênero humano", evitando a marcha cega e irracional da humanidade, motivo pelo qual sua presença deve ser constante.

\section{Referências}

Chiarello, M. G. (2001). Das lágrimas das coisas. Estudo sobre o conceito de natureza em Max Horkheimer. Campinas: Unicamp.

Gabarotta, E. (2014). Hacia una teoría crítica reflexiva. Max Horkheimer, Theodor W. Adorno y Pierre Bourdieu. Buenos Aires: Prometeo Libros.

Horkheimer, M. (1939-1940). The Social Function of Philosophy. Studies in Philosophy and Social Science, VIII.

IX.

. (1941a). Art and mass culture. Studies in Philosophy and Social Science,

(1941b). The End of Reason. Studies in Philosophy and Social Science,

$I X$

(1985a). "Begriff der Bildung". In: Schmidt, A.; Schmid-Noerr, G. (Orgs.). Horkheimer Gesammelte Schriften. Frankfurt am Main: Fischer, v. 8, pp.409-419. [1952].

(1985b). "Philosophie und Studium". In: Schmidt, A.; Schmid-Noerr, G. (Orgs.). Horkheimer Gesammelte Schriften. Frankfurt am Main: Fischer, . v.8, pp.361-377. [1949].

(2015). Eclipse da razão. São Paulo: Unesp. [1947]

Klein, S. (2014). Notas Sobre a Universidade e o Conceito de Formação em Max Horkheimer. Trans/Form/Ação, 37(2), pp.167-184.

(2012). A universidade e a sociologia em Max Horkheimer: teoria, pesquisa e crítica. São Paulo. 300f. Tese (Doutorado). Universidade de São Paulo, Faculdade de Filosofia, Letras e Humanidades, Programa de Pós-Graduação em Sociologia.

Silva, R. C. (2009). "Educação para a resistência em Max Horkheimer". In: Bueno, S. F. (Org.). Teoria crítica e sociedade contemporânea. São Paulo: UNESP. 